\title{
Receptor protein tyrosine phosphatase delta is not essential for synapse maintenance or transmission at hippocampal synapses
}

Kyung Ah Han ${ }^{1,2+}$, Hee-Yoon Lee ${ }^{3 \dagger}$, Dongseok Lim ${ }^{1 \dagger}$, Jungsu Shin ${ }^{1}$, Taek Han Yoon ${ }^{1}$, Xinran Liü ${ }^{4}$, Ji Won Um,2, Se-Young $\mathrm{Choi}^{3}$ and Jaewon $\mathrm{Ko}^{1 *}$ (i)

\begin{abstract}
Members of the leukocyte common antigen-related receptor protein tyrosine phosphatase (LAR-RPTP) family, comprising PTP $\sigma$, PTP $\delta$ and LAR, are key hubs for presynaptic assembly and differentiation in vertebrate neurons. However, roles of individual LAR-RPTP members have not been investigated using member-specific conditional knockout mice. Here, we show that loss of PTP $\delta$ had no overt effect on synapse development in mouse cultured hippocampal neurons. Moreover, loss of PTP $\delta$ in presynaptic CA1 hippocampal neurons did not influence neurotransmitter release in subicular pyramidal neurons, suggesting that PTP $\delta$ is not critical for presynaptic function in vivo. Our results demonstrate that PTP $\delta$ is not essential for synapse maintenance or transmission, at least in the mouse hippocampus, and underscore the importance of using sophisticated genetic approaches to confirm the roles of synaptic proteins.
\end{abstract}

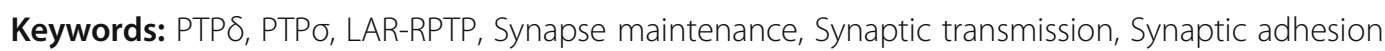

\section{Introduction}

Leukocyte common antigen-related receptor tyrosine phosphatases (LAR-RPTPs) are evolutionarily conserved synaptic organizers in vertebrate neurons [1-3]. LAR-RPTPs bind various postsynaptic ligands to organize multifarious synaptic adhesion pathways that are required for presynaptic assembly and a subset of postsynaptic functions [4-9]. Accumulating evidence from loss-of-function approaches, including constitutive knockout (KO) mice and shorthairpin RNA (shRNA)-mediated knockdown (KD), has lent support to this idea $[2,3,10,11]$. PTP $\delta$ is strongly

\footnotetext{
*Correspondence: jaewonko@dgist.ac.kr

${ }^{\dagger}$ Kyung Ah Han, Hee-Yoon Lee and Dongseok Lim contributed equally to this work.

'Department of Brain and Cognitive Sciences, Daegu Gyeongbuk Institute of Science and Technology (DGIST), 333 Techno Jungangdae-Ro, Hyeonpoong-Eup, Dalseong-Gun, Daegu 42988, South Korea

Full list of author information is available at the end of the article
}

expressed in brains and constitutive PTP $\delta \mathrm{KO}$ has been reported to impair learning, alter long-term synaptic plasticity, and cause abnormal dendritic arborization [12, 13]. Moreover, previous studies have reported that PTP $\delta$ KD produces pleiotropic effects on both presynaptic and postsynaptic processes $[4,6,8,14]$. Although all three members of the vertebrate LAR-RPTP family (PTPб, PTP $\delta$ and LAR) share similar structural, biochemical and ligand-binding profiles [3], individual LAR-RPTP members exhibit unique features. For example, PTPo, but not PTP $\delta$ or LAR, binds to $\operatorname{TrkC}$ receptor tyrosine kinase, whereas PTP $\delta$ specifically binds to IL1RAPL1 (interleukin 1 receptor accessory protein like 1). Moreover, KD analyses in cultured hippocampal neurons have revealed dichotomous roles of PTP $\sigma$ and PTP $\delta$ in regulating maintenance of excitatory and inhibitory synapse development, respectively $[2,5,15,16]$. Although these findings clearly indicate the significance of 
LAR-RPTPs as important synaptic organizers, a more sophisticated approach using conditional KO (cKO) mice deficient in individual LAR-RPTP members is required to precisely evaluate the synaptic role of vertebrate LAR-RPTPs in vivo. A recent paper showed that all three LAR-RPTPs regulate postsynaptic responses mediated by N-methyl-D-aspartate receptors (NMDA-type glutamate receptors) through trans-synaptic mechanism(s), but this study did not examine the presynaptic role of individual LAR-RPTPs [17].

In the present study, we generated mutant mice carrying cKO alleles of PTPS, and used a variety of experimental approaches employing both cultured hippocampal neurons and acute hippocampal slice preparations. We found that, in contrast to KD effects [4], conditional genetic deletion of PTP $\delta$ did not affect synapse numbers, synaptic transmission, or vesicular organization in presynaptic boutons. Moreover, loss of PTP $\delta$ in hippocampal CA1 pyramidal neurons did not affect neurotransmitter release at either excitatory or inhibitory synapses formed on subicular pyramidal neurons. Viewed together, our results suggest that PTP $\delta$ is not essential for synapse maintenance, synaptic transmission, or neurotransmitter release at hippocampal synapses.

\section{Materials and methods}

\section{Cell culture}

HEK293T cells were cultured in Dulbecco's Modified Eagle's Medium (DMEM; WELGENE) supplemented with $10 \%$ fetal bovine serum (FBS; Tissue Culture Biologicals) and $1 \%$ penicillin-streptomycin (Thermo Fisher) at $37^{\circ} \mathrm{C}$ in a humidified $5 \% \mathrm{CO}_{2}$ atmosphere. Cultured primary hippocampal neurons were prepared from embryonic day 17 PTP $\delta$ floxed mouse embryos.

\section{Animals}

The use and care of animals complied with the guidelines and protocols (DGIST-IACUC-17122104-01) for rodent experimentation approved by the Institutional Animal Care and Use Committee of DGIST under standard, temperature-controlled laboratory conditions. PTP $\delta$ conditional knockout mice were generated at Biocytogen Co., Ltd. (Beijing, China). Nestin-Cre (003771, Jackson Research Laboratories) mice were the gift of Dr. Albert Chen (DUKE-NUS, Singapore). Mice were kept on a 12:12 light/dark cycle (lights on at 9:00 am), and received water and food ad libitum. Floxed PTP $\delta\left(\operatorname{PTP} \delta^{\mathrm{f} / \mathrm{f}}\right)$ was generated by flanking exon 12 with loxP sites (See Fig. 1a for details). Nestin-Cre driver line was crossed with $P T P \delta^{\mathrm{f} / \mathrm{f}}$ mice to generate pan-neuronal PTP $\delta$ knockout. Mice were maintained in the C57BL/6 N background. All experimental procedures were performed on male mice, using littermate control without Cre expression.

\section{Expression vectors}

The following plasmids were kindly provided by other investigators: pAAV-hSyn- $\Delta$ Cre-GFP and pAAV-hSyn-Cre-GFP from Dr. Thomas C. Südhof (Stanford University, Palo Alto, CA, USA; and FSW- $\Delta$ Cre and FSW-Cre from Dr. Pascal S. Kaeser (Harvard University, Cambridge, MA, USA).

\section{Antibodies}

Commercially obtained antibodies included: guinea pig polyclonal anti-VGLUT1 (Millipore; RRID: AB_2301751), rabbit polyclonal anti-VGLUT1 (Synaptic Systems; RRID: AB_ 887880), rabbit polyclonal anti-GABA ${ }_{\mathrm{A}} \mathrm{R} \gamma 2$ (Synaptic Systems; RRID: AB_2263066), mouse monoclonal anti-PSD-95 (clone K28/43; Neuromab; RRID: AB_2292909), mouse monoclonal anti-PTPo (clone 17G7.2; MediMabs; RRID: AB_1808357), mouse monoclonal anti-CASK (clone K56A/ 50; NeuroMab; RRID: AB_2068730), rabbit polyclonal antiMunc13-1 (Synaptic Systems; RRID: AB_887733), rabbit polyclonal anti-RIM-BP2 (Synaptic Systems; RRID: AB 2619739), mouse monoclonal anti-ELKS (Sigma-Aldrich; RRID: AB_2100013), mouse monoclonal anti-Synaptophysin (clone SVP-38; Sigma-Aldrich; RRID: AB_477523), mouse monoclonal anti-MAP2 (clone AP-20; Sigma-Aldrich; RRID: AB_477171), rabbit polyclonal anti-MAP2 (Abcam; RRID: AB_776174), mouse monoclonal anti- $\beta$-actin (clone C4; Santa Cruz Biotechnology; RRID: AB_626632), mouse monoclonal anti-GluN1 (clone 54.1; Millipore; RRID: AB_ 94946), rabbit polyclonal anti-Cav2.1 (Synaptic Systems; RRID: AB_2619841), and mouse monoclonal anti-Gephyrin (clone 3B11; Synaptic Systems; RRID: AB_887717). Rabbit polyclonal anti-liprin- $\alpha 2$ (RRID: $A B \_2810258$ ) and rabbit polyclonal anti-liprin- $\alpha 3$ (RRID: AB_2810259) antibodies were gifts of Dr. Susanne Schoch-McGovern (Bonn, Germany); rat polyclonal anti-PTP $\delta$ antibody (RRID: AB_2810260) was the gift of Dr. Fumio Nakamura (Yokohama, Japan); rabbit polyclonal anti-pan-Shank (1172, RRID:AB_2810261), rabbit polyclonal antiGluA1 (1193, RRID: AB_2722772), rabbit polyclonal anti-GluA2 (1195; RRID: AB_2722773), and rabbit polyclonal anti-Homer1 antibodies (1133, RRID, AB 2810985) were the gifts of Dr. Eunjoon Kim (KAIST, Korea).

\section{Neuron culture, immunostaining, imaging, and quantitation}

Hippocampal and cortical mouse neuron cultures were prepared from embryonic day 17 (E17) mouse embryos, as described previously [18]. Mouse cultured neurons were seeded onto coverslips coated with poly-D-lysine (Sigma-Aldrich), and grown in Neurobasal medium supplemented with B-27 (Thermo Fisher), 0.5\% FBS (WELGENE), $0.5 \mathrm{mM}$ GlutaMAX (Thermo Fisher), and sodium pyruvate (Thermo Fisher). 


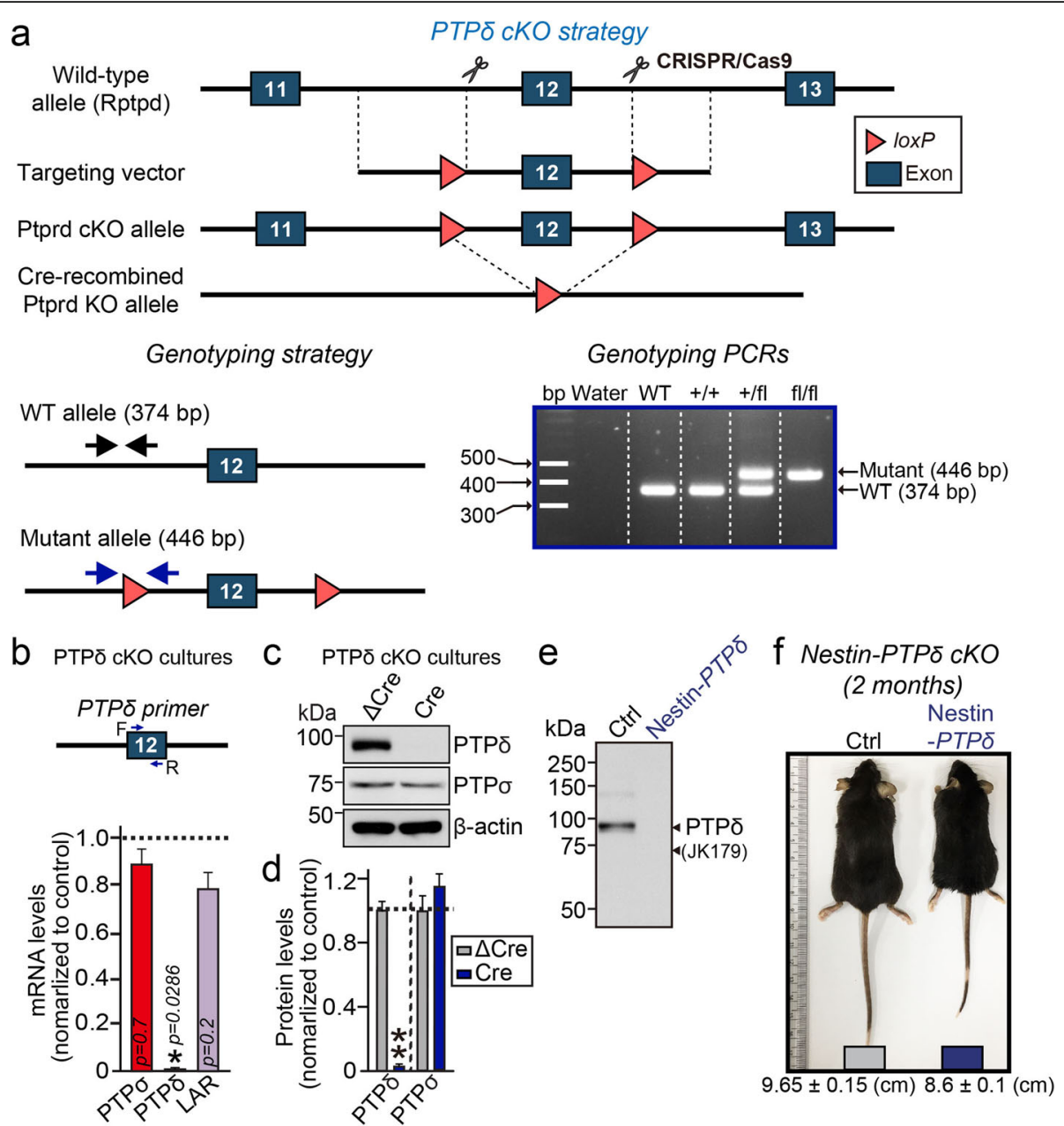

Fig. 1 Generation of PTPS-cKO mice. a cKO strategy for the PTP $\delta$ mouse line. Upper: Targeting of exon 12 of the PTP $\delta$ gene. Bottom left: Primer locations for WT and floxed alleles (arrows). Bottom right: PCR genotyping of WT and PTPS fl/fl mice. b, Quantitative RT-PCR analysis of neuronal mRNA.

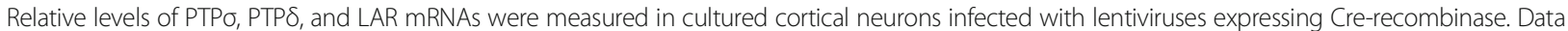
are means \pm SEMs ( $n=3-4$ independent experiments; ${ }^{*} p<0.05$; Mann Whitney U-test). $\mathbf{c}$, $\mathbf{d}$, Representative immunoblot image (c) and quantitative analyses (d) of the level of PTP $\delta$ protein in cultured cortical neurons infected with lentiviruses expressing Cre-recombinase. Data are means \pm SEMs ( $n=6$ independent experiments; ${ }^{* *} p<0.01$; Mann Whitney U-test). e, Representative immunoblot analysis of the level of PTP $\delta$ protein in brain homogenates from 8-week old control and PTP - -cKO mice. Levels of PTP $\delta$ protein were measured in PTP $\delta^{\mathrm{fl} / \mathrm{fl}}$ mice (Ctrl) or PTP $\delta^{\mathrm{fl} / \mathrm{fl}}$ mice crossed with

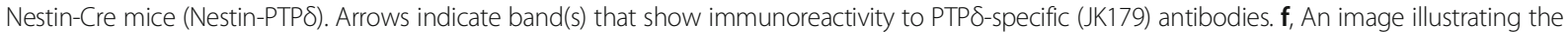
body size of littermate control (Ctrl) and Nestin-PTP $\delta$ mice at 2 months of age. Nestin-PTP $\delta$ mice were significantly smaller than age- and sex-matched Ctrl mice

Cultured neurons were infected with lentiviruses at DIV3-4. For immunocytochemistry, cultured neurons were fixed with $4 \%$ paraformaldehyde/ $4 \%$ sucrose in PBS for 10 or $30 \mathrm{~min}$ at $4{ }^{\circ} \mathrm{C}$, and permeabilized with $0.2 \%$ Triton X-100 in PBS for 10 or $30 \mathrm{~min}$ at $4{ }^{\circ} \mathrm{C}$. Neurons were blocked with $3 \%$ horse serum/0.1\% BSA in PBS for $15 \mathrm{~min}$ at room temperature and incubated with primary and secondary antibodies in blocking solution for $70 \mathrm{~min}$ at room temperature. The primary antibodies were used in these experiments included anti-VGLUT1 (Synaptic Systems; 1:700), anti-GABA ${ }_{\mathrm{A}} \mathrm{R} \gamma 2$ (Synaptic Systems; 1:
500), anti-GluA1 (1193; 1:200), anti-Gephyrin (Synaptic Systems; 1:100), and anti-pan-Shank (1172; 1:200). Images of randomly selected neurons were acquired using a confocal microscope (LSM800, Carl Zeiss) with a $63 \times$ objective lens; all image settings were kept constant during image acquisition. Z-stack images obtained by confocal microscopy were converted to maximal projections, and puncta size and the density of the indicated presynaptic marker proteins were analyzed in a blinded manner using MetaMorph software (Molecular Devices Corp.). 


\section{Production of lentiviruses}

Lentiviruses were produced by transfecting HEK293T cells with three plasmids-lentivirus vectors, psPAX2, and pMD2.G-at a 2:2:1 ratio. After $72 \mathrm{~h}$, lentiviruses were harvested by collecting the media as previously described $[4,19]$.

\section{Production of adeno-associated viruses}

HEK293T cells were co-transfected with the indicated AAV vectors, pHelper and AAV1.0 (serotype 2/9) capsids vectors. After $72 \mathrm{~h}$, the transfected HEK293T cells were collected, and resuspended in PBS, and lysed by subjecting them to four freeze-thaw cycles in an etha$\mathrm{nol} /$ dry ice bath $\left(7 \mathrm{~min}\right.$ each) and a $37^{\circ} \mathrm{C}$ water bath $(5$ $\mathrm{min}$ ). The lysates were centrifuged and the supernatants were mixed with $40 \%$ polyethylene glycol and $2.5 \mathrm{M}$ $\mathrm{NaCl}$ and centrifuged at $2000 \times \mathrm{g}$ for $30 \mathrm{~min}$. The cell pellets were resuspended in HEPES buffer (20 mM HEPES, $115 \mathrm{mM} \mathrm{NaCl}, 1.2 \mathrm{mM} \mathrm{CaCl}_{2}, 1.2 \mathrm{mM} \mathrm{MgCl}_{2}$, and 2.4 $\mathrm{mM} \mathrm{KH}_{2} \mathrm{PO}_{4}, \mathrm{pH}$ 8.0) to which was added an equal volume of chloroform. The mixture was centrifuged at $400 \times \mathrm{g}$ for $5 \mathrm{~min}$ and concentrated three times with a Centriprep centrifugal filter (Cat. 4310, Millipore) at $1220 \times g$ (20 min each) and an Amicon Ultra centrifugal filter (Cat. UFC500396, Millipore) at 16,000 $\times$ g for 30 min. AAVs were titered by treating $1 \mu \mathrm{l}$ of concentrated, filter-sterilized AAVs with $1 \mu \mathrm{l}$ of DNase I (AMPD1; Sigma) for $30 \mathrm{~min}$ at $37^{\circ} \mathrm{C}$ to eliminate any contaminating plasmid DNA. After treatment with $1 \mu \mathrm{l}$ of stop solution (50 mM ethylenediaminetetraacetic acid) for $10 \mathrm{~min}$ at $65^{\circ} \mathrm{C}, 10 \mu \mathrm{g}$ of protease $\mathrm{K}$ (Cat. P2308; Sigma) was added and the sample was incubated for $1 \mathrm{~h}$ at $50^{\circ} \mathrm{C}$. Reactions were stopped by heat inactivation at $95^{\circ} \mathrm{C}$ for $20 \mathrm{~min}$. The final virus titer was quantified by qRT-PCR. Empty AAV vector was used to generate a standard curve for qRT-PCRs targeting GFP sequences.

\section{qRT-PCRs}

Cultured mouse cortical neurons were infected with recombinant lentiviruses at DIV4 and harvested at DIV13 for qRT-PCR using SYBR green qPCR master mix (TaKaRa). Total RNA was extracted from mouse cortical neurons using TRIzol reagent (Invitrogen) according to the manufacturer's protocol. Briefly, cells in each well of a 12-well plate of cultured neurons were harvested and incubated with $500 \mu \mathrm{l}$ TRIzol reagent at room temperature for $5 \mathrm{~min}$. After phenol-chloroform extraction, RNA in the upper aqueous phase was precipitated. cDNA was synthesized from $500 \mathrm{ng}$ of RNA by reverse transcription using a ReverTra Ace- $\alpha$ kit (Toyobo). Quantitative PCR was performed on a CFX96 Touch Real-Time PCR system (BioRad) using $0.5 \mu \mathrm{l}$ of cDNA. The ubiquitously expressed $\beta$-actin was used as an endogenous control. The sequences of the primer pairs used were: mouse Ptprs, $5^{\prime}$ ATCAGAGAGCCCAAGGATCA-3' (forward) and 5'GCCACACACTCGTACACGTT-3' (reverse); mouse Ptprd, 5'-CTCCTTGATCCCCATCTCTG-3' (forward) and 5 '-CAGGGCAGCCACTAAACTTC-3' (reverse); and mouse Ptprf, 5' -CCCGATGGCTGAGTACAACA-3' (forward) and 5'-CATCCCGGGCGTCTGTGA-3' (reverse).

\section{Electron microscopy}

E17 embryonic hippocampi of PTP $\delta$ floxed mice were seeded onto $18 \mathrm{~mm}$ coverslips at densities of 40,000 cells/well. The neurons were infected with lentiviral vectors expressing $\Delta$ Cre or Cre at DIV4. At DIV14, cultured neurons were fixed in $2 \%$ glutaraldehyde, $0.1 \mathrm{M}$ Na-cacodylate buffer, $\mathrm{pH} 7.4$, for $1 \mathrm{~h}$ at room temperature and overnight at $4{ }^{\circ} \mathrm{C}$. The cells were postfixed in $0.5 \% \mathrm{OsO}_{4}$ (osmium tetroxide), $0.8 \% \mathrm{~K}$ ferricyanide at room temperature for $60 \mathrm{~min}$. All specimens were stained en bloc with $2 \%$ aqueous uranyl acetate for $30 \mathrm{~min}$, dehydrated in a graded ethanol series up to 100\%, embedded in Embed 812 resin (Electron Microscopy Science, PA), and polymerized overnight in a $60^{\circ} \mathrm{C}$ oven. Thin sections $(50-60 \mathrm{~nm})$ were cut with a Leica ultramicrotome and post-stained with uranyl acetate and lead citrate. Sample grids were examined using a FEI Tecnai BioTWIN transmission electron microscope running at accelerating voltage of $80 \mathrm{kV}$. Images were recorded with a Morada CCD camera and iTEM (Olympus) software. This protocol allowed the unambiguous staining of membranes of synaptic vesicles as well as of pre- and post-synaptic compartments, resulting in accurate measurements of the nanoscale organization of the synaptic vesicles within nerve endings. To analyze synapse ultrastructure, the lengths of active zone and PSD, tethered vesicles, the membrane proximal vesicles, and total vesicle numbers were quantified using MetaMorph software (Molecular Devices). The numbers of total vesicles and docked vesicles were counted manually, and the distances from the active zone and the PSD to the vesicle center were measured. Vesicles located below $200 \mathrm{~nm}$ were considered membrane-proximal vesicles.

\section{Stereotaxic surgery and virus injections}

4-5-week-old mice were anesthetized by intraperitoneal injection of 2\% 2,2,2-tribromoethanol (Sigma), dissolved in saline, and secured in a stereotaxic apparatus. Viral solutions were injected using a Nanoliter 2010 Injector (World Precision Instruments), including a NanoFil syringe and 33 gauge needle, at a flow rate of $50 \mathrm{nl} / \mathrm{min}$ (injected volume, $500 \mathrm{nl}$ ). The coordinates used for stereotaxic injections targeting the ventral hippocampal CA1 were, relative to the bregma, anteroposterior (AP) 
$-3.1 \mathrm{~mm}$; medial-lateral (ML), $\pm 3.2 \mathrm{~mm}$; and dorsalventral (DV), $-2.5 \mathrm{~mm}$.

\section{In vitro and ex vivo electrophysiology}

\section{Electrophysiology of primary cultured neurons}

Hippocampal neurons obtained from PTP $\delta$ floxed mice were infected on DIV4 with lentiviruses encoding CreEGFP or $\triangle$ Cre-EGFP, followed by analysis at DIV13-16. Pipettes were pulled from borosilicate glass (o.d. $1.5 \mathrm{~mm}$, i.d. $0.86 \mathrm{~mm}$; Sutter Instrument), using a Model $\mathrm{P}^{-97}$ pipette puller (Sutter Instrument). The resistance of pipettes filled with internal solution varied between 3 and $6 \mathrm{M} \Omega$. The internal solution contained $145 \mathrm{mM}$ $\mathrm{CsCl}, 5 \mathrm{mM} \mathrm{NaCl}, 10 \mathrm{mM}$ HEPES, $10 \mathrm{mM}$ EGTA, 0.3 $\mathrm{mM}$ Na-GTP, $4 \mathrm{mM}$ Mg-ATP with $\mathrm{pH}$ adjusted to 7.27.4 with $\mathrm{CsOH}$, and an osmolarity of $290-295 \mathrm{mOsmol} /$ L. The external solution consisted of $130 \mathrm{mM} \mathrm{NaCl}, 4$ $\mathrm{mM} \mathrm{KCl}, 2 \mathrm{mM} \mathrm{CaCl}_{2}, 1 \mathrm{MgCl}_{2}, 10 \mathrm{mM}$ HEPES, and 10 mM D-glucose with $\mathrm{pH}$ adjusted to 7.2-7.4 with $\mathrm{NaOH}$, and an osmolarity of 300-305 mOsmol/L. Whole-cell configuration was generated at RT using MPC-200 manipulators (Sutter Instrument) and a Multiclamp 700B amplifier (Molecular Devices). mEPSCs and mIPSCs were recorded at a holding potential of $-70 \mathrm{mV}$. Receptor-mediated synaptic responses were pharmacologically isolated by applying drug combinations of $50 \mu \mathrm{M}$ picrotoxin, $10 \mu \mathrm{M}$ CNQX, $50 \mu \mathrm{M}$ D-APV and/or $1 \mu \mathrm{M}$ tetrodotoxin. Synaptic currents were analyzed offline using Clampfit 10.5 (Molecular Devices) software.

\section{Acute slice electrophysiology}

Transverse hippocampal formation $(300 \mu \mathrm{m})$ was prepared from 10 to 12-week-old male mice, as described [20]. The mice were anesthetized with isoflurane and decapitated, and their brains were rapidly removed and placed in ice-cold, oxygenated $\left(95 \% \mathrm{O}_{2} / 5 \% \mathrm{CO}_{2}\right)$, low$\mathrm{Ca}^{2+} /$ high $-\mathrm{Mg}^{2+}$ dissection buffer containing $5 \mathrm{mM} \mathrm{KCl}$, $1.23 \mathrm{mM} \mathrm{NaH}_{2} \mathrm{PO}_{4}, 26 \mathrm{mM} \mathrm{NaHCO}, 10 \mathrm{mM}$ dextrose, $0.5 \mathrm{mM} \mathrm{CaCl}, 10 \mathrm{mM} \mathrm{MgCl}$, and $212.7 \mathrm{mM}$ sucrose. Slices were transferred to a holding chamber in an incubator containing oxygenated $\left(95 \% \mathrm{O}_{2} / 5 \% \mathrm{CO}_{2}\right)$ artificial cerebrospinal fluid (ACSF) containing $124 \mathrm{mM}$ $\mathrm{NaCl}, 5 \mathrm{mM} \mathrm{KCl}, 1.23 \mathrm{mM} \mathrm{NaH} \mathrm{PO}_{4}, 2.5 \mathrm{mM} \mathrm{CaCl}_{2}$, $1.5 \mathrm{mM} \mathrm{MgCl} 2,26 \mathrm{mM} \mathrm{NaHCO}_{3}$, and $10 \mathrm{mM}$ dextrose at $28-30{ }^{\circ} \mathrm{C}$ for at least $1 \mathrm{~h}$ before recording. After > $1 \mathrm{~h}$ incubation in ACSF, slices were transferred to a recording chamber with continuous perfusion $(2 \mathrm{ml} /$ $\min )$ by ACSF oxygenated with $95 \% \mathrm{O}_{2} / 5 \% \mathrm{CO}_{2}$ at $23-25^{\circ} \mathrm{C}$. All recordings were performed on pyramidal neurons in the subiculum identified by their size and morphology. Virus-infected neurons were identified by GFP fluorescence. Patch pipettes (4-6 M 2 ) were filled with a solution containing $135 \mathrm{mMK}$-Gluconate, $8 \mathrm{mM}$ $\mathrm{NaCl}, 10 \mathrm{mM}$ HEPES, $2 \mathrm{mM}$ ATP-Na and $0.2 \mathrm{mM}$ GTP-

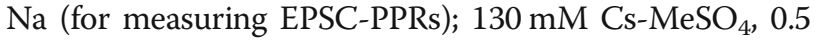
mM EGTA, $5 \mathrm{mM}$ TEA-Cl, $8 \mathrm{mM} \mathrm{NaCl}, 10 \mathrm{mM}$ HEPES, $1 \mathrm{mM}$ QX-314, $4 \mathrm{mM}$ ATP-Mg, 0.4 mM GTP-Na and 10 $\mathrm{mM}$ phosphocreatine- $\mathrm{Na}_{2}$ (for measuring IPSC-PPRs). The extracellular recording solution consisted of ACSF and holding at $0 \mathrm{mV}$ when measuring IPSC-PPRs and supplemented with picrotoxin $(100 \mu \mathrm{M})$ for measuring EPSC-PPRs. Evoked synaptic responses were elicited by stimulation $(0.2 \mathrm{~ms}$ current pulses) using a concentric bipolar electrode (for CA1-subiculum synapses) placed $200-300 \mathrm{~mm}$ in front of postsynaptic pyramidal neurons at intensities that produced $40-50 \%$ of the maximal E/ IPSC amplitude. Recordings were obtained using a Multiclamp 700B amplifier (Molecular Devices) under visual control with differential interference contrast illumination on an upright microscope (BX51WI; Olympus). Data were acquired and analyzed using pClamp 10.7 (Molecular Devices). Signals were filtered at $3 \mathrm{kHz}$ and digitized at 10 $\mathrm{kHz}$ with DigiData 1550 (Molecular Devices).

\section{Data analysis and statistics}

All data are expressed as means \pm SEM. All experiments were repeated using at least three independent cultures, and data were statistically evaluated using a MannWhitney $U$ test, analysis of variance (ANOVA) followed by Tukey's post hoc test, Kruskal-Wallis test (one-way ANOVA on ranks) followed by Dunn's pairwise post hoc test, or paired two-tailed t-test, as appropriate. Prism7.0 (GraphPad Software) was used for analysis of data and preparation of bar graphs. $P$-values $<0.05$ were considered statistically significant (individual $p$-values are presented in figure legends).

\section{Availability of data and materials}

All data generated or analyzed during this study are included in this published article. Any additional information related to the current study is available from the corresponding author on reasonable request.

\section{Results}

\section{Generation of PTPס-cKO mice}

To determine the in vivo synaptic functions of PTP $\delta$, we generated transgenic mice with a deletion of PTP $\delta$ by crossing $P T P \delta^{\mathrm{f} / \mathrm{f}}$ mice (with exon 12 flanked by loxP sites) with a Cre recombinase driver line in which Cre is expressed under control of the Nestin promoter (NestinCre) (Fig. 1a). To assess the effects of endogenous PTP $\delta$ deletion, we induced a global loss of PTP $\delta$ in all neurons by infecting cultured hippocampal neurons from PTP $\delta$ cKO mice at 3-4 days in vitro (DIV) with lentiviruses expressing EGFP-fused nuclear Cre-recombinase, which exhibits high infection efficiency. Infection with a nonfunctional mutant version of Cre-recombinase $(\Delta \mathrm{Cre})$ was used as a control. Global expression of Cre-recombinase 
caused a nearly complete and specific loss of PTP $\delta$ mRNA expression in PTP $\delta$ cKO neurons analyzed at DIV13-14, without affecting PTPo or LAR mRNA (Fig. 1b). Immunoblotting also confirmed complete elimination of PTP $\delta$ protein expression in cultured cortical neurons (Fig. 1c, d) and brain lysates (Fig. 1e) of PTP $\delta$ cKO mice. PTP $\delta$ cKO mice, in which PTP $\delta$ was deleted from the entire brain, were viable and fertile, but showed a modest reduction in body size (Fig. 1f). There were no alterations in expression of various classes of synaptic proteins linked to presynaptic functions (Fig. S1).
Loss of PTP $\delta$ does not reduce the number of excitatory or inhibitory synapses

To evaluate the synaptic role of PTP $\delta$, we infected cultured hippocampal PTP $\delta$ floxed neurons with lentiviruses expressing either $\Delta$ Cre (control) or wild-type Cre recombinase at DIV3-4, and immunostained neurons for various excitatory and inhibitory synaptic markers at DIV14 (Fig. 2a, b). Surprisingly, this immunocytochemical analysis showed no significant change in the density or size of excitatory or inhibitory synaptic puncta (Fig. 2a, b). These results are in stark contrast to previous studies of the

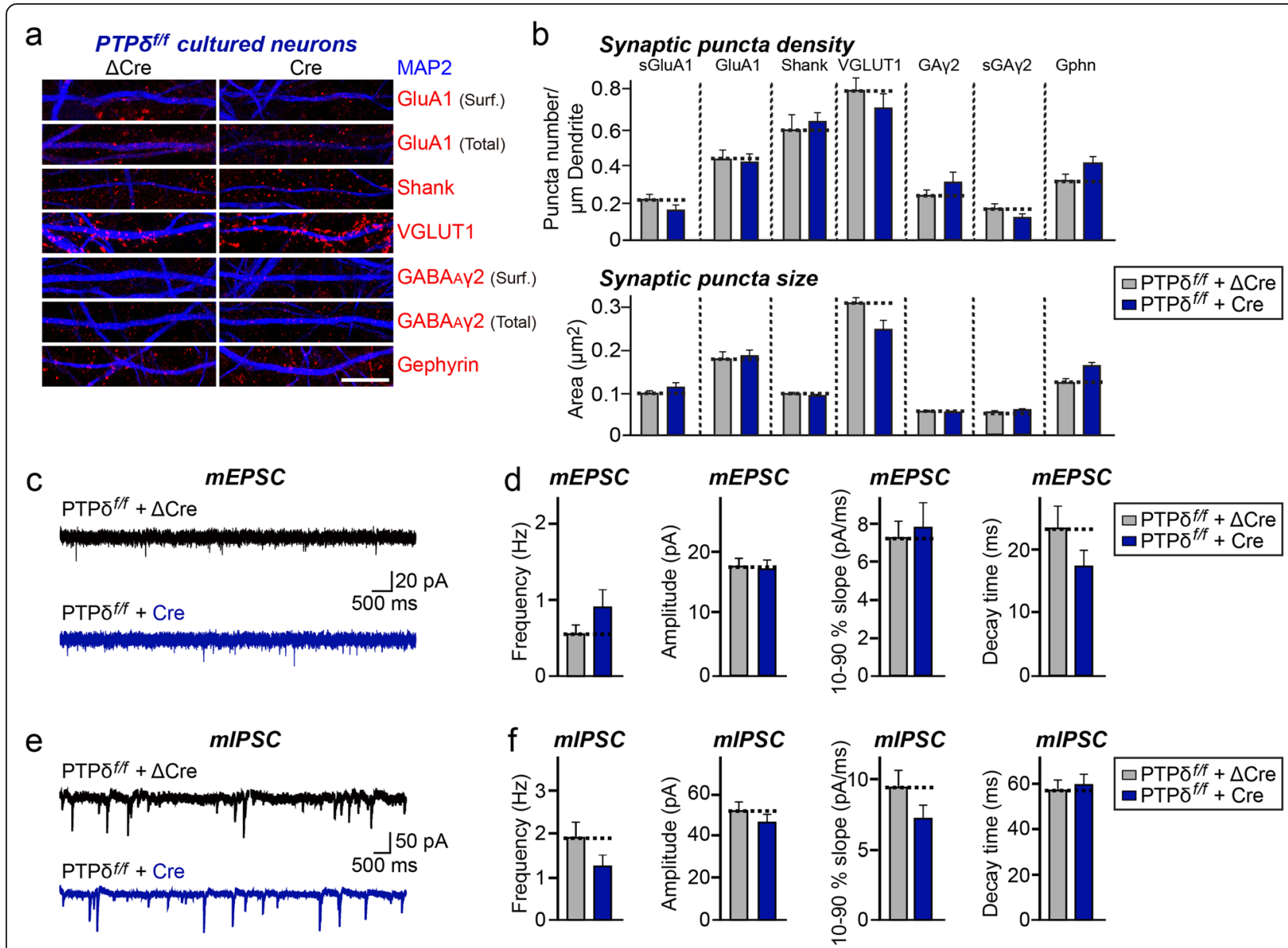

Fig. 2 Loss of PTPS does not affect synapse development or synaptic transmission in cultured hippocampal neurons. a, PTP $\delta$ cKO in cultured hippocampal neurons does not affect excitatory or inhibitory synapse density. Double-immunofluorescence analysis of MAP2 (blue) and the indicated synaptic markers (red) in mature cultured neurons (DIV14) derived from PTP ${ }^{f / f}$ mice, infected with lentiviruses expressing $\Delta C r e$ or Cre at DIV3. Synaptic markers assayed include the excitatory synaptic markers, surface GluA1 (sGluA1), total GluA1, Shank and VGLUT1, and the inhibitory synaptic markers, surface $G A B A_{A} Y 2$ (sGAY2), total GABA Y2, and gephyrin (Gphn). Scale bar: $10 \mu \mathrm{m}$. b. Quantification of images in (a), measuring the density of the indicated synaptic markers. Data are means \pm SEMs ( $n$ denotes the number of analyzed neurons; $\Delta \mathrm{Cre} / \mathrm{sGluA1}, n=14 ; \mathrm{Cre} / \mathrm{sGluA1}, \mathrm{n}=14 ; \Delta \mathrm{Cre} /$ GluA1, $n=14 ;$ Cre/GluA1, $n=15 ; \Delta$ Cre/Shank, $n=21$; Cre/Shank, $n=21 ; \Delta$ CreNGLUT1, $n=16 ;$ Cre/NGLUT1, $n=16 ; \Delta$ Cre/sGABA ${ }_{A} R Y 2, n=16 ;$ Cre/

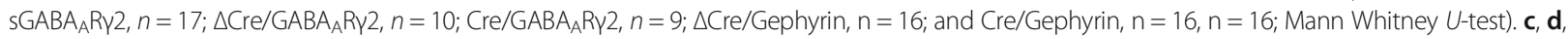
Representative mEPSC traces (c) and quantification of frequencies, amplitudes and kinetics (d) of mEPSCs recorded from cultured hippocampal neurons derived from PTPS ${ }^{f / f}$ mice infected with lentiviruses expressing $\Delta$ Cre or Cre. Data are means \pm SEMs ( $n$ denotes the number of analyzed neurons; $\Delta$ Cre, $n=19 ;$ Cre, $n=13$; unpaired $t$-test). $\mathbf{e}$, $\mathbf{f}$, Representative mIPSC traces (e) and quantification of frequencies, amplitudes and kinetics (f) of mIPSCs recorded from cultured hippocampal neurons derived from PTP $\delta^{\mathrm{f} / \mathrm{f}}$ mice infected with lentiviruses expressing $\Delta$ Cre or Cre. Data are means \pm SEMs ( $n$ denotes the number of analyzed neurons; $\Delta C r e, n=18 ; C r e, n=16$; unpaired $t$-test) 
effect of PTP $\delta$ KD, which reported a specific reduction in inhibitory synapse numbers $[4,15]$.

\section{Loss of PTP $\delta$ does not impair synaptic transmission}

To assess whether PTP $\delta$ loss affects synaptic transmission, we performed an electrophysiological assessment of cultured hippocampal neurons (Fig. 2c-f). Cultured hippocampal PTP $\delta$ floxed neurons were infected with lentiviruses expressing either $\Delta \mathrm{Cre}$ (control) or Cre recombinase at DIV3, and miniature excitatory postsynaptic currents (mEPSCs) and miniature inhibitory postsynaptic currents (mIPSCs) were recorded at DIV14-16 (Fig. 2c-f). In line with results from imaging experiments (Fig. 2a, b), lentivirus-mediated global loss of PTP $\delta$ had no effect on baseline synaptic transmission at excitatory or inhibitory synapses (Fig. 2c-f). Again, these findings are different from previous reported results for PTP $\delta \mathrm{KD}$ showing specific reductions in inhibitory synaptic transmission [4].

\section{Loss of PTPS does not alter synaptic vesicle tethering or active zone (AZ) architectures}

To further probe whether PTP $\delta$ loss affects synaptic structures, we imaged presynaptic terminals and postsynaptic densities of chemically fixed, cultured hippocampal neurons from PTP $\delta$ floxed mice infected with lentiviruses expressing either $\Delta \mathrm{Cre}$ (control) or Cre recombinase using transmission electron microscopy (TEM), as previously

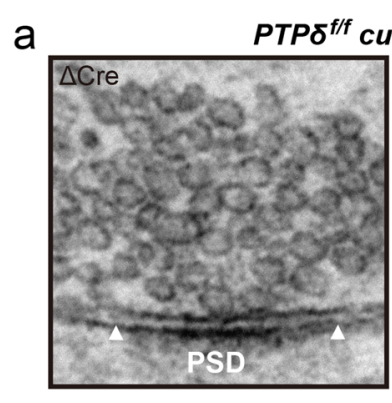

b
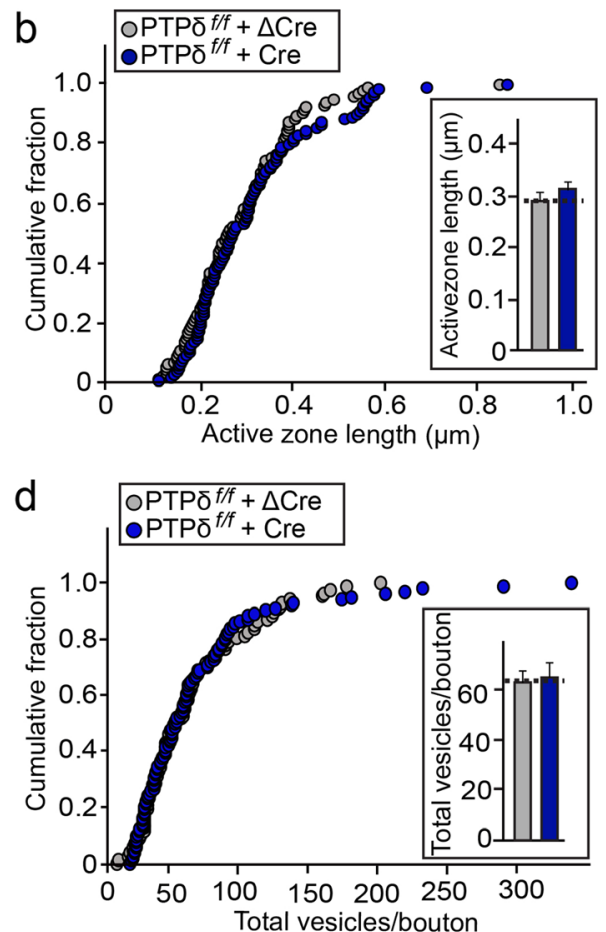

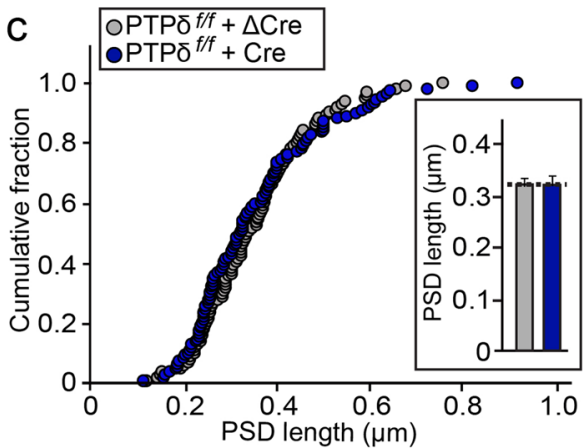

e

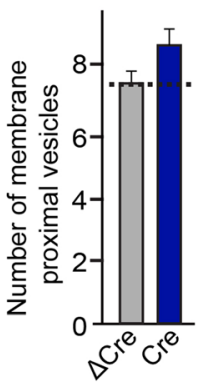

f

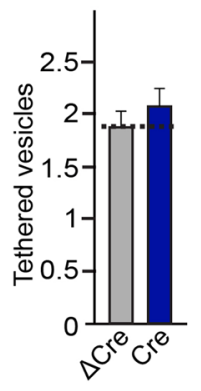

Fig. 3 Loss of PTPS does not induce abnormal organization of synapse structures in cultured hippocampal neurons. a, Representative electron micrographs of cultured hippocampal neurons from PTP $\delta^{f / f}$ mice infected with lentiviruses expressing $\Delta$ Cre (control) or Cre. b, c, PTP $\delta$ deletion has no effect on the length of synaptic membranes. Cumulative distributions of the lengths of AZ (b) and PSD (c) for the indicated genotypes. Data are means \pm SEMs ( $n$ denotes the number of analyzed neurons; $\Delta$ Cre, $n=88 ; C r e, n=105 ;$ Mann Whitney U-test). $\mathbf{d}$-f, Total number of vesicles per bouton (d), membrane-proximal vesicles (e), and membrane-tethered vesicles $(\mathbf{f})$ in control and PTP $\delta$-deficient synapses. Data are means \pm SEMs ( $n$ denotes the number of analyzed neurons; $\Delta C r e, n=88$; Cre, $n=105 ;$ Mann Whitney $U$-test) 
described [21] (Fig. 3). TEM analyses of cultured neurons showed that length of active zone (AZ) and postsynaptic density (PSD) were similar between PTP $\delta$-deficient and control presynaptic terminals (Fig. 3a-c). Moreover, PTP $\delta$-deficient and control presynaptic terminals contained similar numbers of total vesicles, and that the distribution of vesicles in PTP $\delta$-deficient terminals was similar that in control presynaptic terminals (Fig. 3d). In addition, the numbers of membrane-proximal vesicles (defined as vesicles $<100 \mathrm{~nm}$ from the presynaptic AZ membrane) in PTP $\sigma$-deficient presynaptic terminals were also comparable to those in control presynaptic terminals (Fig. 3e). Moreover, the number of tethered vesicles, defined as vesicular structures docked at presynaptic AZ membranes, was also similar (Fig. 3f). Overall, these results suggest that PTP $\delta$ is not crucial for maintaining the structural organization of either presynaptic AZs or PSDs in hippocampal neurons.

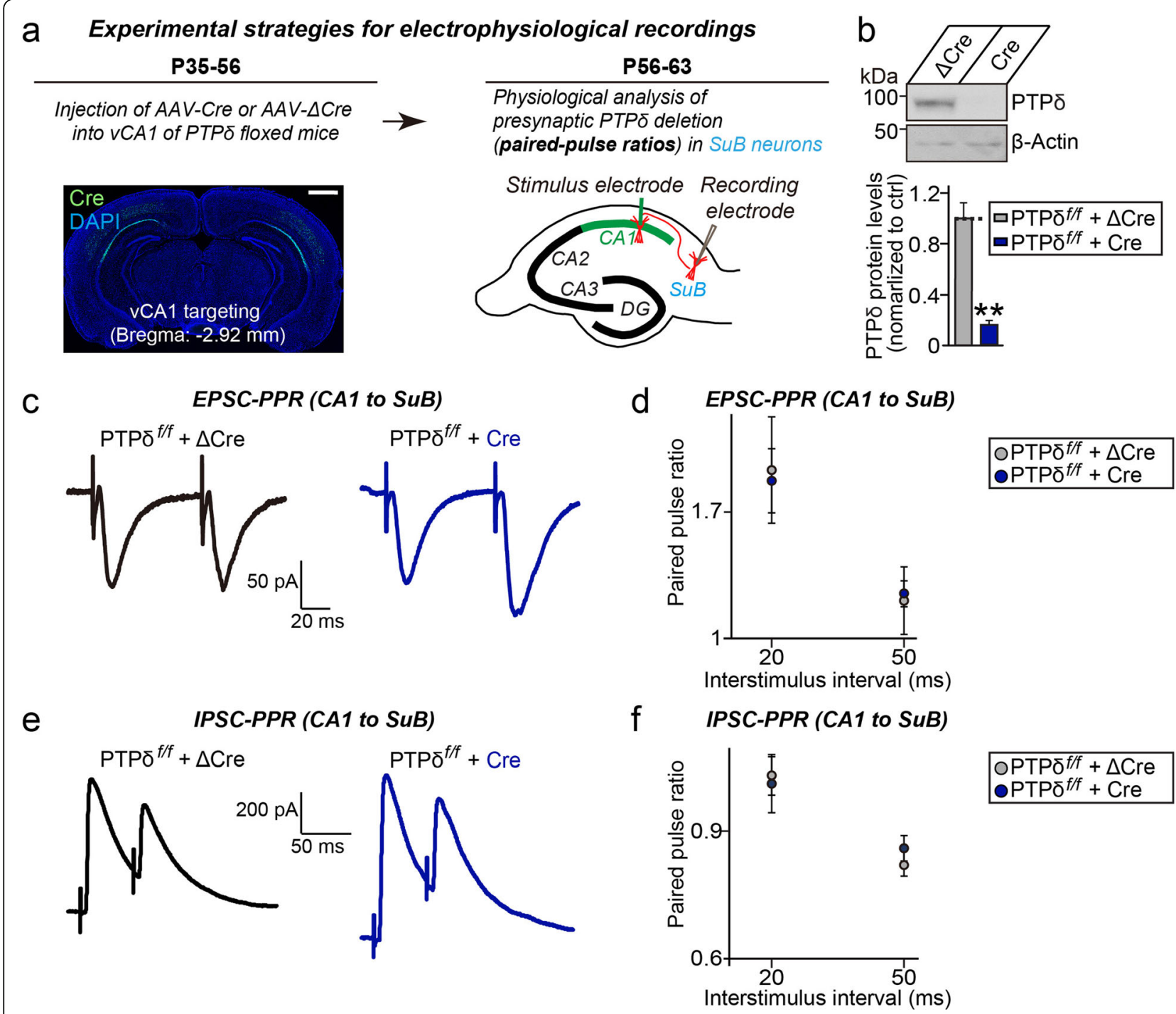

Fig. 4 Presynaptic deletion of PTP $\delta$ in hippocampal CA1 neurons does not affect neurotransmitter release at excitatory or inhibitory synapses in postsynaptic subicular (SuB) pyramidal neurons. a, Experimental strategies for electrophysiological recordings in hippocampal SuB neurons innervated by PTPS-deficient CA1 neurons. Representative coronal section showing EGFP expression after AAV-Cre injections into the ventral CA1 region of PTP $\delta$ floxed mice. Scale bar, $1 \mathrm{~mm}$. b. Analysis of AAV-Cre expression in the hippocampal CA1 region of PTPS-cKO mice. Representative immunoblot analyses (top) with PTPS antibodies showing deletion of PTP $\delta$ protein in vivo. Infected mouse brain lysates were collected after stereotactic injection of AAV-Cre or AAV-

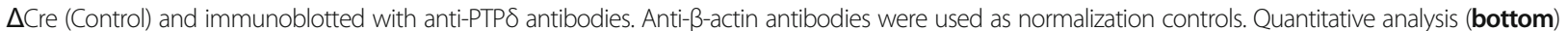
of immunoblotting experiments. Data are means \pm SEMs ( $n=5$ mice/group; ${ }^{* *} p<0.01$; Mann Whitney U-test). $\mathbf{c}$, e, Representative traces of paired-pulse ratios (PPRs) of EPSCs (c) and IPSCs (e) in hippocampal CA1-SuB synapses at two different interstimulus intervals (20 and 50 ms). d, f, EPSC-PPRs (d) and IPSC-PPRs (f) in hippocampal CA1-SuB synapses as a function of the indicated interstimulus intervals. Data are means \pm SEMs (n denotes the number of analyzed neurons; $\Delta$ Cre [EPSC-PPR], $n=6$; Cre [EPSC-PPR], $n=7 ; \Delta$ Cre [IPSC-PPR], $n=16$; and Cre [IPSC-PPR], $n=12$; two-tailed student's t-test) 
Loss of PTPS in presynaptic neurons does not affect neurotransmitter release at postsynaptic target neurons Lastly, we sought to address the role of PTP $\delta$ in regulating presynaptic neurotransmitter release in acute hippocampal slice preparation. In these experiments, we targeted hippocampal CA1-to-subicular synapses for analyses because of its amenability for presynaptic manipulations by stereotactic injection of viruses into the hippocampal CA1 region [22, 23]. We stereotactically injected adenoassociated viruses (AAVs) expressing either $\triangle \mathrm{Cre}$ (Control) or Cre recombinase into hippocampal CA1 region of $P T P \delta^{\mathrm{f} / \mathrm{f}}$ mice. PTP $\delta \mathrm{KO}$ in vivo was validated by quantitative immunoblot analyses using hippocampal CA1 tissue lysates of AAV-injected mice (Fig. 4a, b). We then recorded the paired-pulse ratios (PPRs) of excitatory (EPSC-PPRs) or inhibitory (IPSC-PPRs) postsynaptic currents in subicular pyramidal neurons. Again, neither EPSC-PPRs nor IPSCPPRs were altered in subicular neurons from Cre-infected $P T P \delta^{\mathrm{f} / \mathrm{f}}$ mice (Fig. $4 \mathrm{c}-\mathrm{f}$ ), suggesting that PTP $\delta$ is not essential for neurotransmitter release at excitatory or inhibitory synapses in the hippocampus in vivo.

\section{Discussion}

There is extensive literature support for the idea that PTP $\delta$ is important for synapse development $[2,24]$. The current study using PTP $\delta$ floxed mice infected with Cre recombinase, in conjunction with imaging, electrophysiology and electron microscopy, clearly demonstrated that conditional deletion of PTP $\delta$ does not significantly affect most synaptic parameters. These results were quite surprising and unexpected. Some discrepancies between the results of this study and previous studies-even including those by our laboratory-may be attributable to differences in developmental changes caused by constitutive $\mathrm{KO}$ and the well-documented off-target effects of RNA interference. Secondary effects triggered by KD may also have contributed to previously observed severe phenotypes; for example, PTP $\delta$ KD induced PTP $\sigma$ upregulation in neurons, and vice versa, whereas PTP $\delta \mathrm{KO}$ did not [4] (Fig. S1). It is also plausible that functional redundancies between LAR-RPTP proteins contribute to masking PTP $\delta$ loss-induced phenotypes in our experimental approaches. A recent study employing triple-cKO mice lacking all three LAR-RPTPs showed that, overall, the effects of LAR-RPTP triple cKO on cultured hippocampal neurons and hippocampal Schaffer-collateral synapses were marginal [17]. Remarkably, this latter study showed that triple LAR-RPTP cKO in presynaptic CA3 neurons strongly suppressed NMDA-type postsynaptic responses in postsynaptic CA1 neurons [17]. Our recent results using РТР $\sigma-\mathrm{cKO}$ mice did not reveal a similar trans-synaptic effect on postsynaptic responses [25]. Thus, testing whether presynaptic PTPS is mainly involved in contributing to the reported trans-synaptic regulation of postsynaptic responses is warranted. However, it is equally likely that all three LAR-RPTPs are required for operation of this process in vivo. Regardless of precise answer(s), the current study indicates the importance of confirmatory analyses using a sophisticated system and approaches in elucidating functions of synaptic proteins in vivo.

As limitations, it could be argued that the approaches employed in the current study are not sufficiently sensitive to detect subtle changes in synapse properties. Moreover, the selection of experimental preparations may preclude detection of synaptic roles of PTP $\delta$ at in vivo synapses. Although PTP $\delta$ mRNA is widely distributed across rodent brain areas [26], it remains to be determined whether endogenous PTP $\delta$ protein is widely expressed or is restricted to a subset of certain neuron types or neural circuits. The lack of this information still hinders our ability to fully address the synaptic roles of PTP $\delta$ proteins. Development of effective PTP $\delta$-specific antibodies suitable for highresolution in vivo imaging is also warranted, as has similarly been shown for other cell-adhesion proteins [27]. With such tools and information in hand, it should be possible to use the PTP $\delta$-cKO mice developed in the current study to unravel the canonical and non-canonical roles of PTP $\delta$ at appropriate in vivo neural circuits. Doing so may provide a better understanding of how LAR-RPTPs act as multivalent signaling platforms in presynaptic neurons.

\section{Supplementary information}

Supplementary information accompanies this paper at https://doi.org/10. 1186/s13041-020-00629-x.

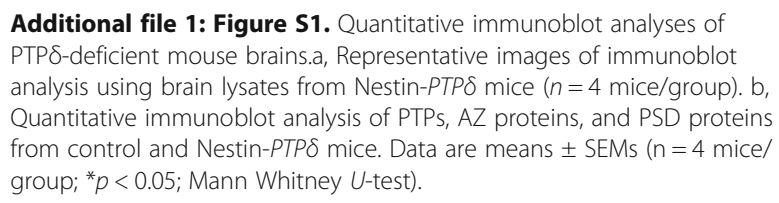

\section{Abbreviations}

AAV: Adeno-associated virus; cKO: Conditional knockout; EPSC: Excitatory postsynaptic current; IPSC: Inhibitory postsynaptic current; KD: Knockdown; LAR-RPTP: Leukocyte common antigen-related receptor protein tyrosine phosphatase; NMDA: N-methyl-D-aspartate; PPR: Paired-pulse ratio; TEM: Transmission electron microscopy; VGLUT1: Vesicular glutamate transporter 1

\section{Acknowledgements}

We are grateful to Jinha Kim (DGIST) for technical assistance.

\section{Authors' contributions}

J.K. conceived the project. K.A.H., H.Y.L., D.L. and X.L. performed the experiments. K.A.H., H.Y.L., D.L., J.S., T.H.Y., J.W.U., S.Y.C. and J.K. analyzed the data. J.W.U., S.Y.C. and J.K. supervised the project. J.K. wrote the paper with input from the other authors. The authors read and approved the final manuscript.

\section{Funding}

This study was supported by grants from Brain Research Program through the NRF funded by the Ministry of Science, ICT \& Future Planning

(2017M3C7A1023470 to J.K.) and the DGIST R\&D Program of the Ministry of 
Science and ICT (20-CoE-BT-01 to K.A.H., J.W.U. and J.K.). The authors declare no competing financial interests.

\section{Availability of data and materials}

The datasets used and/or analysed during the current study are available from the corresponding author on reasonable request.

\section{Ethics approval}

All procedures and protocols were approved by the Institutional Animal Care and Use Committee of Daegu Gyeongbuk Institute of Science and Technology (DGIST). All experiments were conducted according to the guidelines and protocols for rodent experimentation approved by the Institutional Animal Care and Use Committee of DGIST.

\section{Consent for publication}

Not applicable.

\section{Competing interests}

The authors declare that they have no competing interests.

\section{Author details}

'Department of Brain and Cognitive Sciences, Daegu Gyeongbuk Institute of Science and Technology (DGIST), 333 Techno Jungangdae-Ro, Hyeonpoong-Eup, Dalseong-Gun, Daegu 42988, South Korea. ${ }^{2}$ Core Protein Resources Center, DGIST, 333 Techno Jungangdae-Ro, Hyeonpoong-Eup, Dalseong-Gun, Daegu 42988, South Korea. ${ }^{3}$ Department of Physiology and Neuroscience, Dental Research Institute, Seoul National University School of Dentistry, Seoul 03080, South Korea. ${ }^{4}$ Department of Cell Biology, Yale University School of Medicine, New Haven, CT 06510, USA.

Received: 9 March 2020 Accepted: 29 May 2020

Published online: 17 June 2020

\section{References}

1. Südhof TC. The presynaptic active zone. Neuron. 2012;75:11-25.

2. Han KA, Um JW, Ko J. Intracellular protein complexes involved in synapse assembly in presynaptic neurons. Adv Protein Chem Struct Biol. 2019;116: 347-73.

3. Um JW, Ko J. LAR-RPTPs: synaptic adhesion molecules that shape synapse development. Trends Cell Biol. 2013;23:465-75.

4. Han KA, Ko JS, Pramanik G, Kim JY, Tabuchi K, Um JW, Ko J. PTPsigma drives excitatory presynaptic assembly via various extracellular and intracellular mechanisms. J Neurosci. 2018:38:6700-21.

5. Takahashi H, Arstikaitis P, Prasad T, Bartlett TE, Wang YT, Murphy TH, Craig AM. Postsynaptic TrkC and presynaptic PTPsigma function as a bidirectional excitatory synaptic organizing complex. Neuron. 2011;69:287-303.

6. Yim YS, Kwon Y, Nam J, Yoon HI, Lee K, Kim DG, Kim E, Kim CH, Ko J. Slitrks control excitatory and inhibitory synapse formation with LAR receptor protein tyrosine phosphatases. Proc Natl Acad Sci. 2013;110:4057-62.

7. Yoshida T, Yasumura M, Uemura T, Lee SJ, Ra M, Taguchi R, Iwakura Y, Mishina M. IL-1 receptor accessory protein-like 1 associated with mental retardation and autism mediates synapse formation by trans-synaptic interaction with protein tyrosine phosphatase delta. J Neurosci. 2011;31: 13485-99.

8. Li Y, Zhang P, Choi TY, Park SK, Park H, Lee EJ, Lee D, Roh JD, Mah W, Kim R, et al. Splicing-dependent trans-synaptic SALM3-LAR-RPTP interactions regulate excitatory synapse development and locomotion. Cell Rep. 2015;12: 1618-30.

9. Choi Y, Nam J, Whitcomb DJ, Song YS, Kim D, Jeon S, Um JW, Lee SG, Woo J, Kwon SK, et al. SALM5 trans-synaptically interacts with LAR-RPTPs in a splicing-dependent manner to regulate synapse development. Sci Rep. 2016;6:26676.

10. Takahashi H, Craig AM. Protein tyrosine phosphatases PTPdelta, PTPsigma, and LAR: presynaptic hubs for synapse organization. Trends Neurosci. 2013; 36:522-34.

11. Han KA, Jeon S, Um JW, Ko J. Emergent synapse organizers: LAR-RPTPS and their companions. Int Rev Cell Mol Biol. 2016;324:39-65.

12. Nakamura F, Okada T, Shishikura M, Uetani N, Taniguchi M, Yagi T, Iwakura Y, Ohshima T, Goshima Y, Strittmatter SM. Protein tyrosine phosphatase delta mediates the Sema3A-induced cortical basal dendritic Arborization through the activation of Fyn tyrosine kinase. J Neurosci. 2017:37:7125-39.

13. Uetani N, Kato K, Ogura H, Mizuno K, Kawano K, Mikoshiba K, Yakura H, Asano M, Iwakura Y. Impaired learning with enhanced hippocampal long-term potentiation in PTPdelta-deficient mice. EMBO J. 2000;19: 2775-85.

14. Dunah AW, Hueske E, Wyszynski M, Hoogenraad CC, Jaworski J, Pak DT, Simonetta A, Liu G, Sheng M. LAR receptor protein tyrosine phosphatases in the development and maintenance of excitatory synapses. Nat Neurosci. 2005:8:458-67.

15. Ko JS, Pramanik G, Um JW, Shim JS, Lee D, Kim KH, Chung GY, Condomitti $\mathrm{G}$, Kim HM, Kim H, et al. PTPsigma functions as a presynaptic receptor for the glypican-4/LRRTM4 complex and is essential for excitatory synaptic transmission. Proc Natl Acad Sci U S A. 2015;112:1874-9.

16. Takahashi H, Katayama K, Sohya K, Miyamoto H, Prasad T, Matsumoto Y, Ota M, Yasuda H, Tsumoto T, Aruga J, Craig AM. Selective control of inhibitory synapse development by Slitrk3-PTPdelta trans-synaptic interaction. Nat Neurosci. 2012;15:389-98 S381-382.

17. Sclip A, Südhof TC. LAR receptor phospho-tyrosine phosphatases regulate NMDA-receptor responses. Elife. 2020;9:e53406. https://doi.org/10.7554/eLife. 53406.

18. Ko J, Soler-Llavina GJ, Fuccillo MV, Malenka RC, Südhof TC. Neuroligins/ LRRTMs prevent activity- and Ca2+/calmodulin-dependent synapse elimination in cultured neurons. J Cell Biol. 2011:194:323-34.

19. Hsia HE, Kumar R, Luca R, Takeda M, Courchet J, Nakashima J, Wu S, Goebbels S, An W, Eickholt BJ, et al. Ubiquitin E3 ligase Nedd4-1 acts as a downstream target of PI3K/PTEN-mTORC1 signaling to promote neurite growth. Proc Natl Acad Sci U S A. 2014;111:13205-10.

20. Noh K, Lee H, Choi TY, Joo Y, Kim SJ, Kim H, Kim JY, Jahng JW, Lee S, Cho SY, Lee SJ. Negr 1 controls adult hippocampal neurogenesis and affective behaviors. Mol Psychiatry. 2019;24:1189-205.

21. Acuna C, Liu X, Südhof TC. How to make an active zone: unexpected universal functional redundancy between RIMs and RIM-BPs. Neuron. 2016; 91:792-807.

22. Aoto J, Martinelli DC, Malenka RC, Tabuchi K, Südhof TC. Presynaptic neurexin-3 alternative splicing trans-synaptically controls postsynaptic AMPA receptor trafficking. Cell. 2013:154:75-88.

23. Anderson GR, Aoto J, Tabuchi K, Foldy C, Covy J, Yee AX, Wu D, Lee SJ, Chen L, Malenka RC, Südhof TC. beta-Neurexins control neural circuits by regulating synaptic endocannabinoid signaling. Cell. 2015;162:593-606.

24. Südhof TC. Synaptic Neurexin complexes: a molecular code for the logic of neural circuits. Cell. 2017:171:745-69.

25. Han KA, Lee H-Y, Lim D, Um JW, Choi S-Y, Ko J, et al. PTPs controls presynaptic organization of neurotransmitter release machinery at excitatory synapses. iscience. 2020;23(6):101203. https://doi.org/10.1016/j.isci.2020. 101203

26. Kwon SK, Woo J, Kim SY, Kim H, Kim E. Trans-synaptic adhesions between netrin-G ligand-3 (NGL-3) and receptor tyrosine phosphatases LAR, proteintyrosine phosphatase delta (PTPdelta), and PTPsigma via specific domains regulate excitatory synapse formation. J Biol Chem. 2010;285:13966-78.

27. Sando R, Jiang $X$, Südhof TC. Latrophilin GPCRs direct synapse specificity by coincident binding of FLRTs and teneurins. Science. 2019;363(6429): eaav7969. https://doi.org/10.1126/science.aav/7969.

\section{Publisher's Note}

Springer Nature remains neutral with regard to jurisdictional claims in published maps and institutional affiliations.

Ready to submit your research? Choose BMC and benefit from:

- fast, convenient online submission

- thorough peer review by experienced researchers in your field

- rapid publication on acceptance

- support for research data, including large and complex data types

- gold Open Access which fosters wider collaboration and increased citations

- maximum visibility for your research: over $100 \mathrm{M}$ website views per year

At $\mathrm{BMC}$, research is always in progress.

Learn more biomedcentral.com/submission 